DOI:

\title{
PEMBERDAYAAN REMAJA DALAM PEMANFAATAN SISA SAMPAH MENJADI PUPUK ORGANIK CAIR DI DUSUN KADISORO GILANGHARJO PANDAK BANTUL
}

\author{
Muchsin Maulana ${ }^{1}$, Putri Widi Nugraheni ${ }^{2}$, \\ Universitas Ahmad Dahlan ${ }^{12}$ \\ Email: $\underline{\text { muchsin.maulana@ikm.uad.ac.id }}{ }^{1}$
}

\begin{abstract}
ABSTRAK
Pertambahan jumlah penduduk di perkotaan yang pesat berdampak terhadap peningkatan jumlah sampah yang di hasilkan. Peningkatan jumlah sampah yang tidak diikuti oleh perbaikan dan peningkatan sarana dan prasarana pengelolaan sampah mengakibatkan permasalahan sampah menjadi komplek, antara lain sampah tidak terangkut dan terjadi pembuangan sampah liar, sehingga dapat menimbulkan berbagai penyakit, kota kotor, bau tidak sedap, mengurangi daya tampung sungai dan lain-lain. Pelatihan ini bertujuan untuk meningkatkan pengetahuan, kesadaran, kemauan, dan kemampuan Remaja Kadisoro Gilangharjo Pandak, Bantul dalam mengelola sampah. Metode yang digunakan dalam pengabdian ini melalui ceramah, pengarahan kepada remaja terkait bahan-bahan yang dapat dijadikan pupuk organik cair. Selanjutnya adalah praktik langsung bersama remaja pandak bantul dengan arahan dan pendampingan asisten pada saat pengabdian. Hasil dari kegiatan ini pada saat praktik, remaja di dusun Kadisoro Gilangharjo Pandak bantul sangat antusias, remaja sudah sangat familiar dengan pemanfaatan sampah, akan tetapi pemanfaatan sampah menjadi pupuk cair masih jarang ditemui. Remaja mendengarkan dengan seksama, mulai dari penyampaian materi sampai praktik langsung, dimulai dengan pengarahan oleh asisten secara langsung. Kemudian remaja secara aktif mengikuti dan mempraktikan secra langsung.
\end{abstract}

Kata kunci: Pemanfaatan Sampah, Pupuk Cair

\begin{abstract}
Rapid population growth in urban areas has an impact on increasing the amount of waste produced. The increase in the amount of waste that is not followed by the improvement and improvement of waste management facilities and infrastructure has resulted in the problem of waste becoming a complex, including un-transported waste and illegal waste disposal, so that it can cause various diseases, dirty cities, bad smells, reduce river capacity and etc. This training aims to increase the knowledge, awareness, willingness and ability of Adolescent Kadisoro Gilangharjo Pandak, Bantul in managing waste. The method used in this service is through lectures, directing to adolescents related to materials that can be used as liquid organic fertilizer. Next is the direct practice with teenagers Pandak Bantul with direction and assistant assistance at the time of dedication. During the practice, adolescents in Kadisoro Gialngharjo hamlet Pandak bantul were very enthusiastic, adolescents were very familiar with the use of garbage, but the use of waste into liquid fertilizer is still rare. Teenagers listen carefully, starting from the delivery of material to direct practice, starting with direct instruction by the assistant. Then adolescents actively follow and practice immediately.
\end{abstract}

Keywords: Utilization of Waste, Liquid Fertilizers 


\section{PENDAHULUAN}

Pertambahan jumlah penduduk di perkotaan yang pesat berdampak terhadap peningkatan jumlah sampah yang di hasilkan. Peningkatan jumlah sampah yang tidak diikuti oleh perbaikan dan peningkatan sarana dan prasarana pengelolaan sampah mengakibatkan permasalahan sampah menjadi komplek, antara lain sampah tidak terangkut dan terjadi pembuangan sampah liar, sehingga dapat menimbulkan berbagai penyakit, kota kotor, bau tidak sedap, mengurangi daya tampung sungai dan lain-lain (Ayu, 2008).

Masalah sampah mutlak harus ditangani secara bersama-sama antara pemerintah, lembaga swadaya masyarakat dan masyarakat itu sendiri. Karena itu dibutuhkan kesadaran dan komitmen bersama menuju perubahan sikap,perilaku dan etika yang berbudaya lingkungan. Sebagai upaya menggugah kepedulian dalam penanganan permasalahan lingkungan, khususnya persampahan serta untuk menciptakan kualitas lingkungan pemukiman yang bersih dan ramah lingkungan maka, harus dilakukan perubahan paradigma pengelolaan sampah dengan cara: 1. pengurangan volume sampah dari sumbernya dengan pemilihan, atau pemrosesan dengan teknologi yang sederhana seperti composting dengan skala rumah tangga atau skala lingkungan, 2. peran serta masyarakat dalam pengelolaan sampah di koordinir oleh kelompok swadaya masyarakat (KSM), kelompok ini bertugas mengkoordinir pengelolaan kebersihan lingkungan (Ayu, 2008).

Salah satu timbulan sampah yang paling banyak adalah sampah rumah tangga 84,64\%, kemudian sampah pasar 2,52\% dan sampah kawasan industri 2,58\%. Peran serta masyarakat merupakan salah satu faktor penting untuk memecahkan permasalahan sampah di perkotaan. Sampai saat ini peran serta masyarakat secara umum hanya sebatas pembuangan sampah saja belum sampai pada tahapan pengelolaan sampah yang dapat bermanfaat kembali bagi masyarakat. Pengelolaan sampah yang paling sederhana dengan memisahkan sampah organik dan anorganik memerlukan sosialisasi yang intensif dari pemerintah kepada masyarakat (Dinas Kebersihan Kota Semarang, 2007). Pengelolaan sampah yang dapat dilakukan oleh masyarakat untuk mengurangi jumlah sampah yang masuk keTPA diantaranya adalah pengomposan. Manfaat lain teknik pengelolaan sampah dengan pengomposan adalah dapat menjadikan pupuk yang dapat menyuburkan tanaman. Pelatihan ini bertujuan untuk meningkatkan pengetahuan, kesadaran, kemauan, dan kemampuan Remaja Kadisoro Gilangharjo Pandak, Bantul dalam mengelola sampah.

\section{METODE}


Metode yang digunakan dalam pengabdian ini melalui ceramah, pengarahan kepada remaja terkait bahan-bahan yang dapat dijadikan pupuk organik cair. Selanjutnya adalah praktik langsung bersama remaja pandak bantul dengan arahan dan pendampingan asisten pada saat pengabdian. Berikut alur pembuatan pupuk oraganik cair, pemilahan sampah yang mudah membusuk dan menghasilkan air - kemudian mencampurkan sampah yang sudah dipilah dengan cairan EM4 - cairan tersebut dipergunakan agar pupuk cair siap untuk digunakan sebagai pupuk cair.

\section{HASIL, PEMBAHASAN, DAN DAMPAK}

Kegiatan pada tahap persiapan yaitu persiapan materi, pengurusan ijin serta persiapan alat dan bahan. Pengurusan ijin dibantu oleh teman-teman karang Taruna Remaja Kadisoro Gilangharjo Panndak Bantul. Alat dan bahan yang perlu disiapkan adalah LCD proyektor serta mempersiapakan bahan-bahan yang diperlukan untuk pembuatan pupuk cair. Peserta undangan berasal dari Dusun Kadisoro, Gilangharjo Panndak Bantul. Kegiatan ini dilakukan Pendopo Manunggal Kadisoro Gialngharjo Pandak Bantul.

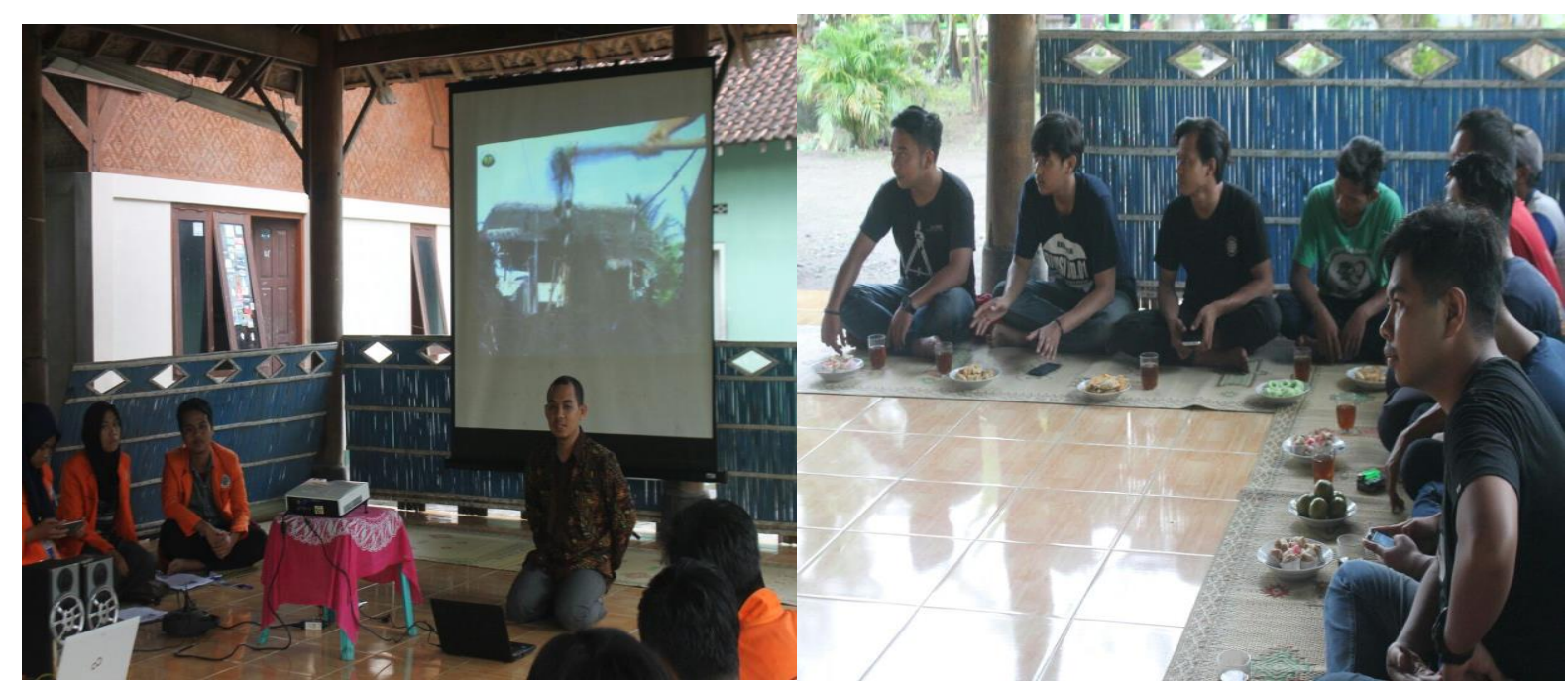

Gambar 1. Kegiatan ceramah pembuatan pupuk cair 


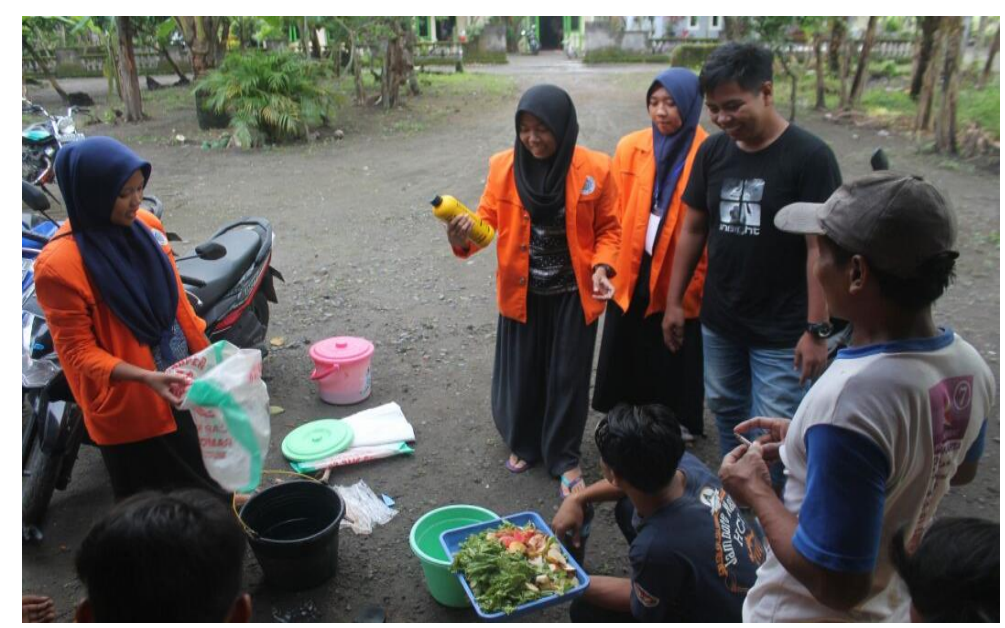

Gambar 2. Praktek pembuatan pupuk cair

Pada saat praktik, remaja di dusun Kadisoro Gialngharjo Pandak bantul sangat antusias, remaja sudah sangat familiar dengan pemanfaatan sampah, akan tetapi pemanfaatan sampah menjadi pupuk cair masih jarang ditemui. Remaja mendengarkan dengan seksama, mulai dari penyampaian materi sampai praktik langsung, dimulai dengan pengarahan oleh asisten secara langsung. Kemudian remaja secara aktif mengikuti dan mempraktikan secra langsung. Gambar diatas menjelaskan bahwa remaja dengan serius mendengarkan pemaparan materi dan dilanjutkan dengan praktik langsung pembuatan pupuk cair.

Pelaksanaan kegiatan ini tidak ada kendala yang berarti. Kendala yang dirasakan yaitu kehadiran peserta tidak mencapai $100 \%$. Peserta undangan adalah remaja di dusun Kadisoro Gialngharjo Pandak Bantul. kegiatan penyuluhan ini berlangsung kondusif dan bahkan peserta sangat antusias mengikuti kegiatan

\section{SIMPULAN}

Pengetahuan peserta sudah sangat memahami tentang pengolahan sampah namun tentang pembuatan pupuk organik cair masih sesuatu hal yang jarang ditemui di dusun Kadisoro Gilangharjo Pandak Bantul. Pelaksanaan pengabdian berjalan dengan lancar tanpa kendala yang berarti.

\section{DAFTAR PUSTAKA}

Ayu, NI K, A, 2008. Peran serta masyarakat dalam pengelolaan sampah rumah tangga. Tesis. Program Magister Lingkungan. Program Pasca Sarjana. Universitas Diponegoro

Dinas Kebersihan Kota Semarang, 2007. Profil Dinas Kebersihan Kota Semarang. Semarang. 


\section{UCAPAN TERIMAKASIH}

Ucapan terima kasih, kami haturkan kepada remaja Karang Taruna Kadisoro Gilangharjo Pandak Bantul. Serta perangkat desa yang telah berkenan meminjamkan termpat pertemuan kepada kami. 
